\title{
Flight Test Evaluation for Tilt Rotor Unmanned Aerial Vehicle Development
}

\author{
A A Arif ${ }^{1,}$, , R A Sasongko ${ }^{1}$ \\ 1 Department of Aerospace Engineering, Institut Teknologi Bandung, Indonesia \\ * Correspondence: adamadilaarif@gmail.com
}

Received: 18 February 2021; Accepted: 17 May 2021; Published: 30 June 2021

Tiltrotor Unmanned Aerial Vehicle (UAV) is type of UAV that combine fixed wing (FW) and multirotor (VTOL) configuration in order to be able to perform instant transition from one configuration to another. Tiltrotor UAV has advantage to perform takeoff and landing from limited space such as plantation farm, forest, and residential area. Tiltrotor also can carry various mission since it has 2 configuration such as cargo drone, safer payload dropping, and mapping. In this research tiltrotor UAV designed with ruddervator (V-Tail) configuration with 3 motors in total, 2 motors placed on main wing with tilting capability and 1 motor placed at the end of fuselage as pitch controller in VTOL mode. Test flight will be conducted and evaluated to test UAV capability in hovering and transition from one mode to another.

Keywords: Tiltrotor UAV, flight test, ruddervator (V-Tail), multirotor (VTOL), fixed wing

\section{Introduction}

Tiltrotor UAV is Unmanned Aerial Vehicle that combine fixed wing (FW) and multirotor (VTOL) configuration in order to be able to perform instant transition from one configuration to another. Tiltrotor UAV has the advantage to perform takeoff and landing from limited space such as plantation farm, forest, and residential area. Tiltrotor also can carry various mission since it has 2 configuration such as cargo drone, safer payload dropping, and mapping. In this research tiltrotor UAV designed with ruddervator (V-Tail) configuration with 3 motors in total based on several well studied tiltrotor configuration [3], 2 motors placed on main wing with tilting capability and 1 motor placed at the end of fuselage as pitch controller in VTOL mode as shown in Figure 1. This research is continuation from previous paper which discussed about numerical model of tilt rotor [1].

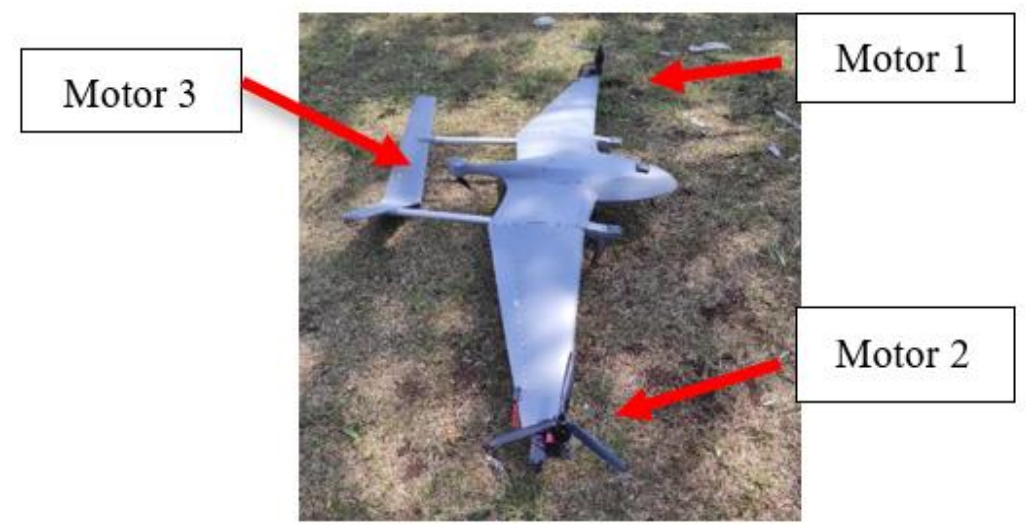

Figure 1. Aircraft Final Configuration 
This Tiltrotor UAV has initial designed specification shown in Table 1 with only 2 motors being placed on the main wing. But in the process this configuration proved to be not effective to control vehicle's pitch attitude when flying in VTOL mode so that third motor has to be added to give aircraft pitch control authority.

Table 1. Aircraft Specification

\begin{tabular}{|l|l|l|}
\hline \multicolumn{3}{|l|}{ Platform } \\
\hline Wingspan & 1800 & $\mathrm{~mm}$ \\
\hline Length & 1100 & $\mathrm{~mm}$ \\
\hline MTOW & 4.5 & $\mathrm{Kg}$ \\
\hline Propulsion System & \multicolumn{2}{|l|}{} \\
\hline Type & Brushless Motor \\
\hline Power & 1750 & W/axis \\
\hline Thrust & 4500 & Gram \\
\hline Battery & \multicolumn{2}{|l}{} \\
\hline Capacity & $115 \mathrm{Wh} / 6 \mathrm{~S} 5200$ & $\mathrm{mAh}$ \\
\hline Voltage & 22.2 & $\mathrm{~V}$ \\
\hline
\end{tabular}

\begin{tabular}{|l|l|l|}
\hline Performance \\
\hline Endurance & 30 & Min. \\
\hline Stall speed & 11 & $\mathrm{~m} / \mathrm{s}$ \\
\hline Cruise speed & $16-18$ & $\mathrm{~m} / \mathrm{s}$ \\
\hline Third motor & \multicolumn{2}{|l|}{} \\
\hline RPM/V & 800 & $\mathrm{KV}$ \\
\hline Weight & 140 & $\mathrm{G}$ \\
\hline Diameter & 35 & $\mathrm{~mm}$ \\
\hline Length & 58.5 & $\mathrm{~mm}$ \\
\hline
\end{tabular}

\section{Flight Test Procedures}

In order to understand how the tiltrotor, behave in hover and transition flight, flight test will be conducted three times with each test flight following procedure as shown in Figure 3.

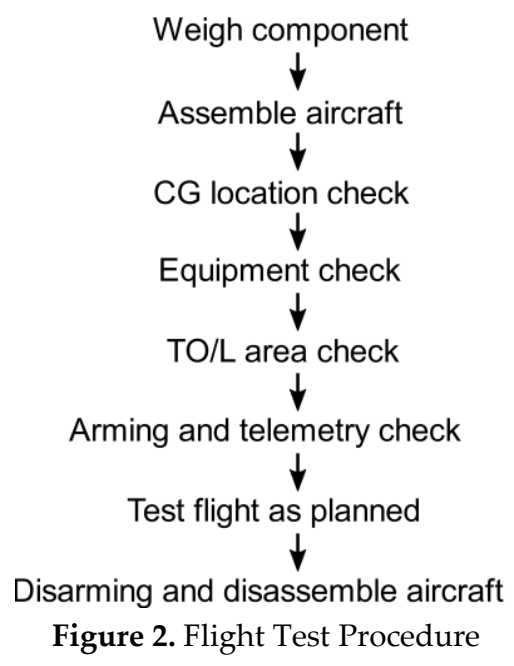

In test flight procedure, each component must be weighed in order to calculate takeoff weight to make sure it is conformed with initial design. After takeoff weight confirmed, aircraft's CG must be checked as well to conform with the designed location. When takeoff weight and CG location confirmed, equipment for test flight need to be checked such as remote, spare motor, spare telemetry and can proceed to test flight site. For all test flight, it was conducted in open field to ensure safety.

When the area is clear with no one except test crew is present, arming procedure can be started by connecting the battery and check the telemetry status on the laptop. The pilot then will make a call regarding to aircraft readiness and wind condition at the time whether go or no go for the test flight. When all crew ready, test flight then executed as planned for that day and documented as well. When test flight is done, the battery then disconnected to disarm the aircraft to ensure the motor is not running. 


\section{Flight Test Scenarios}

Each flight test conducted had different scenario depends on the objective that day. In this development of tiltrotor, flight test conducted three times in total.

\subsection{First Flight Test}

On first flight test, the objective is trying to hover using 2-motor configuration with main motor acting as pitch controller by tilting its motor axis as shown in Figure 6. The controller method used in this flight is PID controller [4] by feeding back its attitude (pitch and roll) then PID gave command to adjust motor tilt angel as shown in Figure 7.

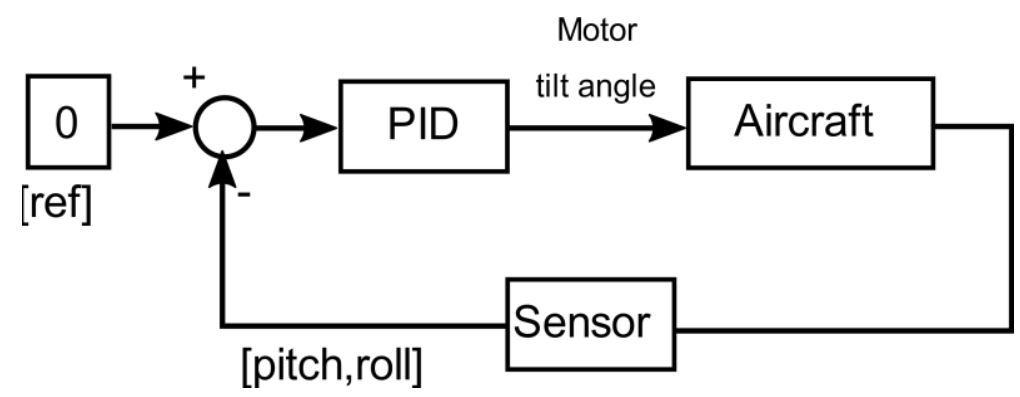

Figure 3. PID Scheme for 2-motor configuration

\subsection{Second Flight Test}

On the second test flight the objective is to perform hover flight with 3-motor configuration. The hover flight will be controlled by PID by feeding back aircraft attitude and PID will gave command to each motor to produce thrust difference as shown in Figure 8. The thrust difference between T1+T2 and T3 will produce pitching moment while difference between T1 and T2 will produce roll moment as shown in Figure 9.

Thrust

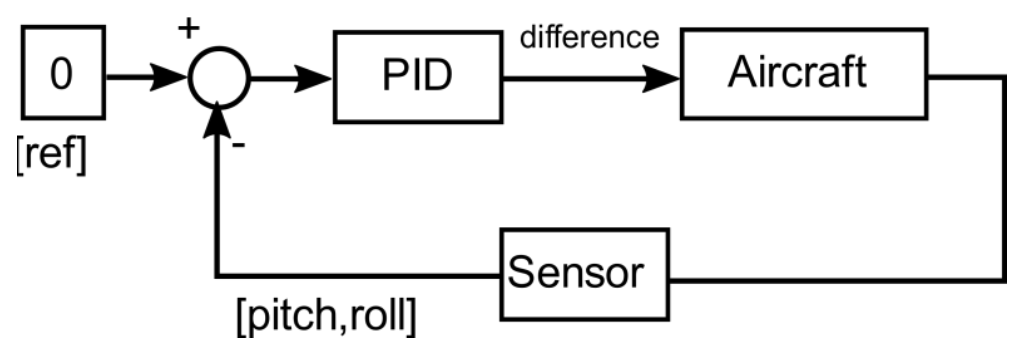

Figure 4. PID Scheme for 3-motor configuration

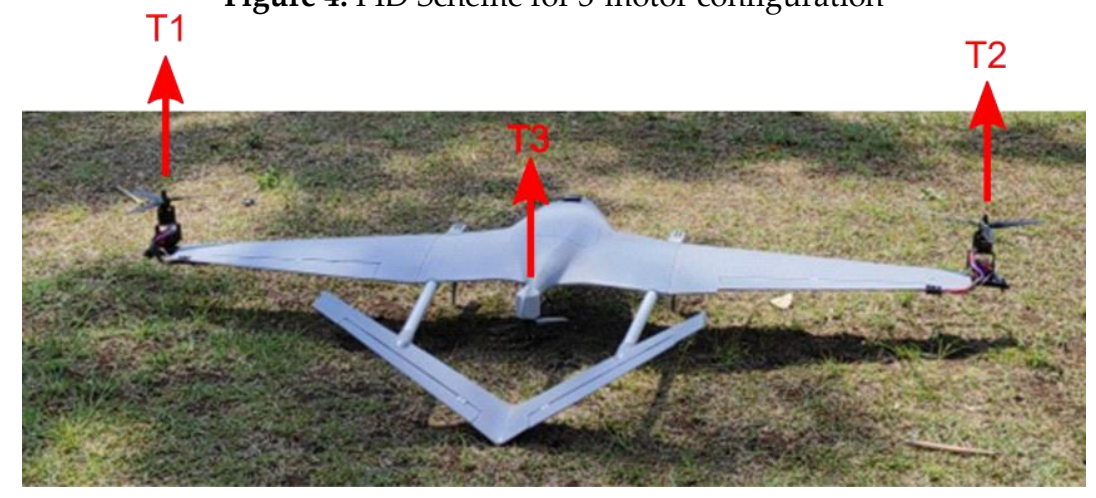

Figure 5. Thrust Produced from Each Motor 


\subsection{Third Flight Test}

On the third test flight the objective is to perform full flight by following mission profile as shown in Figure 10 with aircraft performing vertical takeoff and hover at certain altitude, after it stabilized, main motor on the wing will tilting 90 degrees facing forward so the aircraft will fly on fixed-wing mode as shown in Figure 11. The aircraft then performing cruise and 180 degrees turn to approach landing zone, while descending, the main rotor will tilt 90 degrees back facing upward to flying on VTOL mode. After it stabilized, then the pilot will reduce the thrust for landing phase.

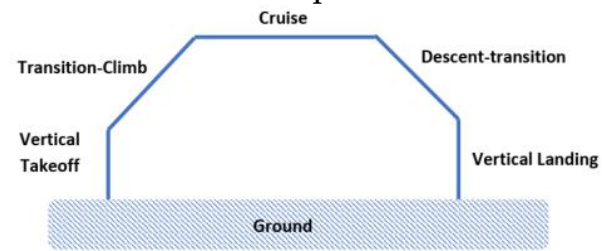

Figure 6. Third Test Flight Mission Profile

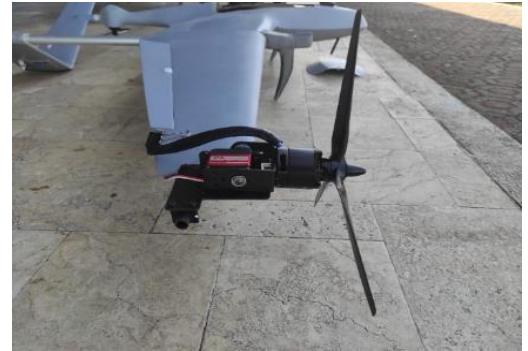

Figure 7. Main Motor Direction on FW mode

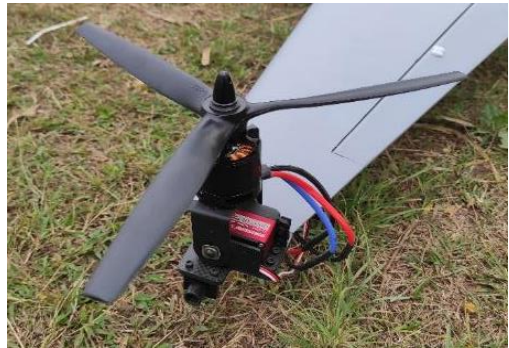

Figure 8. Main Motor Direction on VTOL mode

\section{Flight Test Results}

Flight test results will be presented in this chapter with first flight test will be conducted for 2motor configuration while second and third flight test for 3-motor configuration.

\subsection{First Flight Test}

On the first test flight, the aircraft can't perform hover flight properly as shown in Figure 9 until Figure 10 sequentially. The aircraft can hover for a few seconds, but when there is wind that affect its attitude, the aircraft didn't have pitch control authority to counteract the disturbance, so the pilot decided to cut the throttle to land the aircraft.

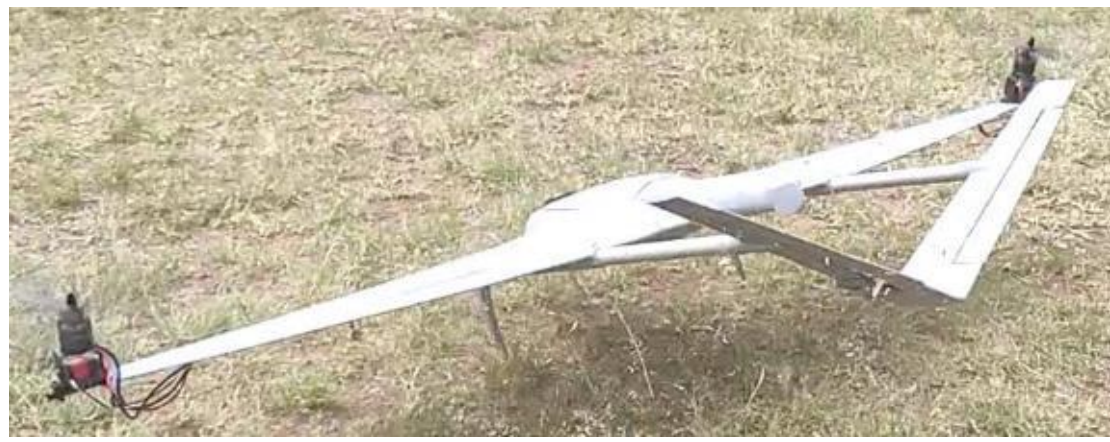

Figure 9. Aircraft Can't Counteract the Disturbance 


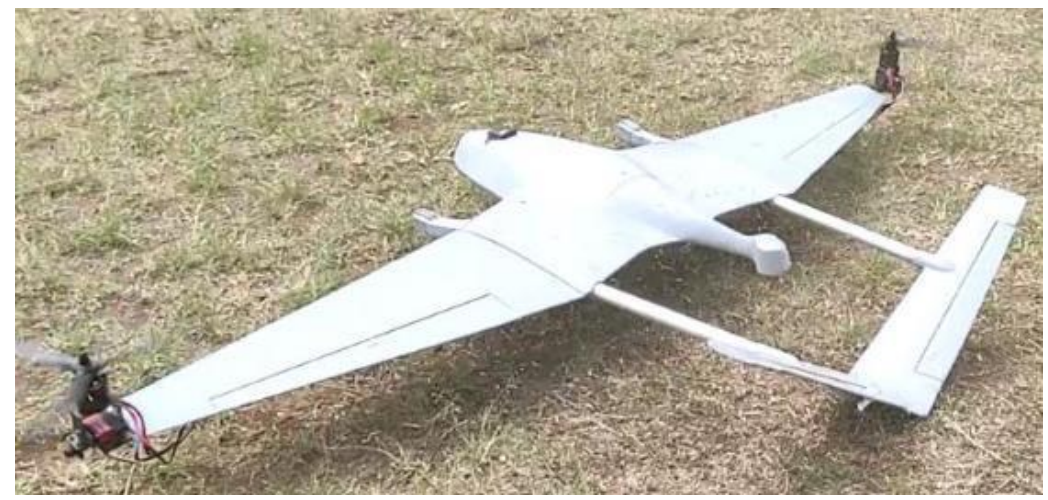

Figure 10. Pilot Cut the Throttle and Aircraft Safely landed

\subsection{Second Flight Test}

On the second flight, third motor already installed to give the aicraft pitch control authority when flying in VTOL mode. In this occasion, the parameter for PID is tuned so that the aircraft has quite good response when there are disturbances from environment. In this test flight the disturbance comes from pilot itself to mimic disturbance from environment. The results for this test flight are shown in Figure 11 and Figure 12 for pitch disturbance. The result in this test flight was the aircraft can maintain its attitude (roll and pitch) on zero degree when there are disturbances.

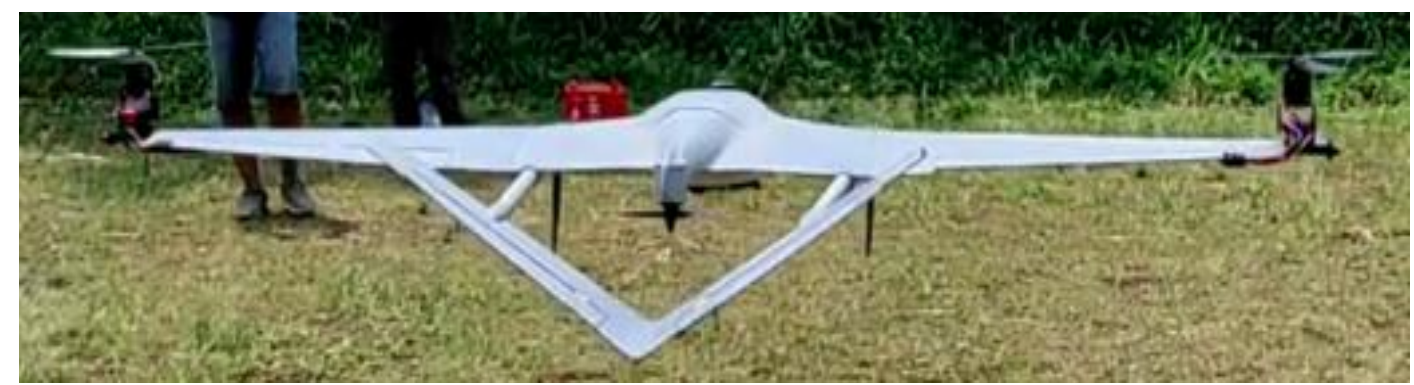

Figure 11. Aircraft Given Pitch Disturbance

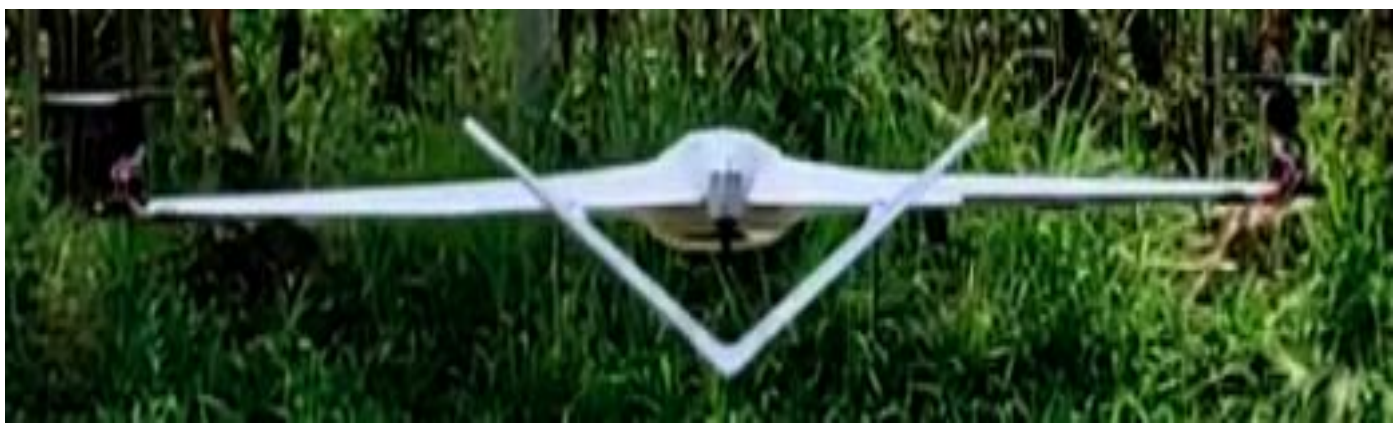

Figure 12. Aircraft Went Back to its Attitude Reference (0 pitch angle)

\subsection{Third Flight Test}

On the third test flight the aircraft can perform full flight phase from VTOL mode to FW and from FW to VTOL mode properly as shown in Figure 13 until Figure 19 even the aircraft landed on its tail first. 


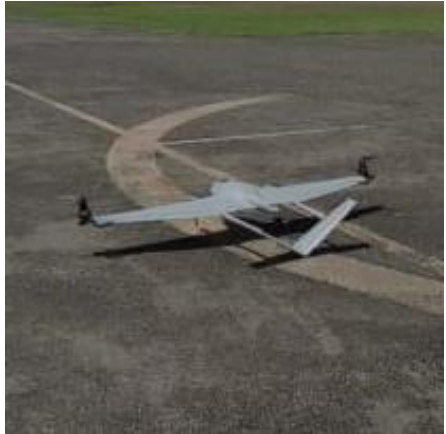

Figure 13. Aircraft preparing for takeoff

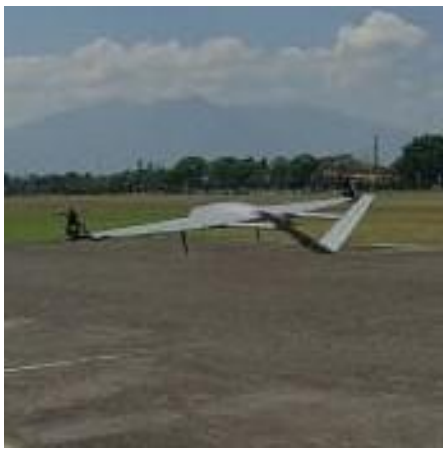

Figure 14. Aircraft hovering

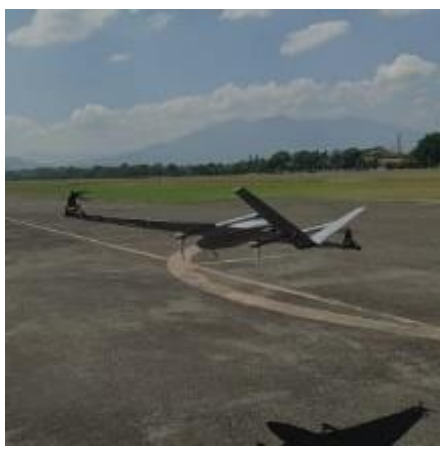

Figure 15. Aircraft gaining speed and transitioning to FW mode

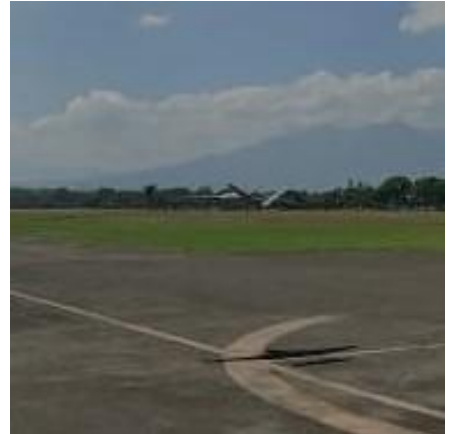

Figure 16. Aircraft on FW mode and climbing

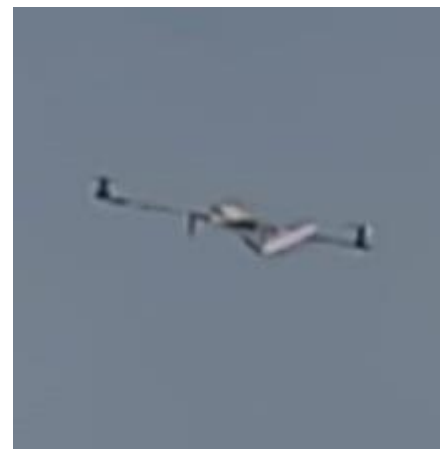

Figure 17. Aircraft transitioning from FW to VTOL

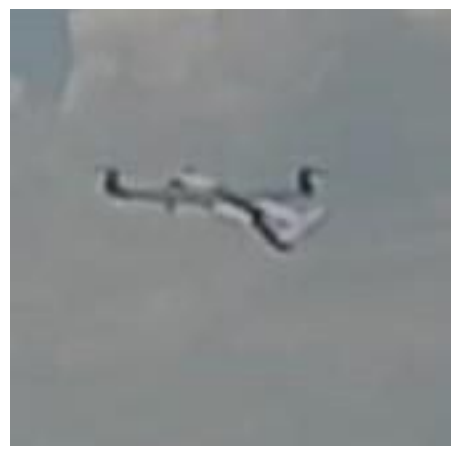

Figure 18. Aircraft on VTOL mode and prepare for landing

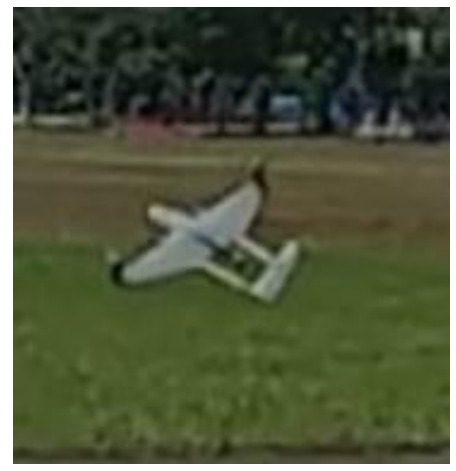

Figure 19. Aircraft perform landing 


\section{Flight Test Analysis}

On the first test flight, the aircraft flying on initial design configuration with 2-motor configuration to perform hover flight. Because of its configuration, the aircraft was lacked of pitch control authority in VTOL mode so when there was slight disturbance the aircraft can't counteract it. So, on the second phase of the development, the third motor has to be added on the aft fuselage in order to give the aircraft pitch control authority when flying in VTOL mode. The result of third motor addition on the aircraft is it can hover properly because when there are pitch and roll disturbances, the difference from each motor create moment that counteract those disturbances as shown in Figure 20. When the aircraft can hover properly, the third test flight can be conducted.

Third test flight conducted with objective full flight with mission profile shown in Figure 6 . The data obtained from third test flight presented in Figure 20 until Figure 24 which show estimation of aircraft altitude, attitude, elevator deflection, ground speed, and motor's PWM. The data filtered using Savitzky-Golay Filter method to smoothing the curve and reduce noise [5]. Figure 20 depicted responses for all motor, M1 and M2 are motors that located on the main wing, while M3 is motor that located in aft fuselage of the aircraft. Flying mode showed by red dashed line in Figure 20. In early and final stage of flight at 0-10 seconds and around 35-70 seconds the third motor's PWM value is similar to both M1 and M2 to create pitch control authority in VTOL mode, when the main motor (M1 and M2) tilting to 90 degrees facing forward, the third motor's PWM was in idle value so that pitch control authority is taken by elevator.

When aircraft is transitioning from VTOL to FW flying mode, aircraft's altitude is slightly decreased as shown in Figure 23 because the thrust direction is slowly facing forward rather than all motor facing upward, so that the speed of the aircraft is slowly increasing as well as shown in Figure 24 and the elevator is quite effective to produce pitching moment as shown in Figure 21 and Figure 22. When the aircraft approaching landing zone, the main motor direction changing from facing forward to upward so that the total lift is not only come from lifting surface but also the thrust direction, therefore the altitude is slightly increased and the ground speed is reduced as well.

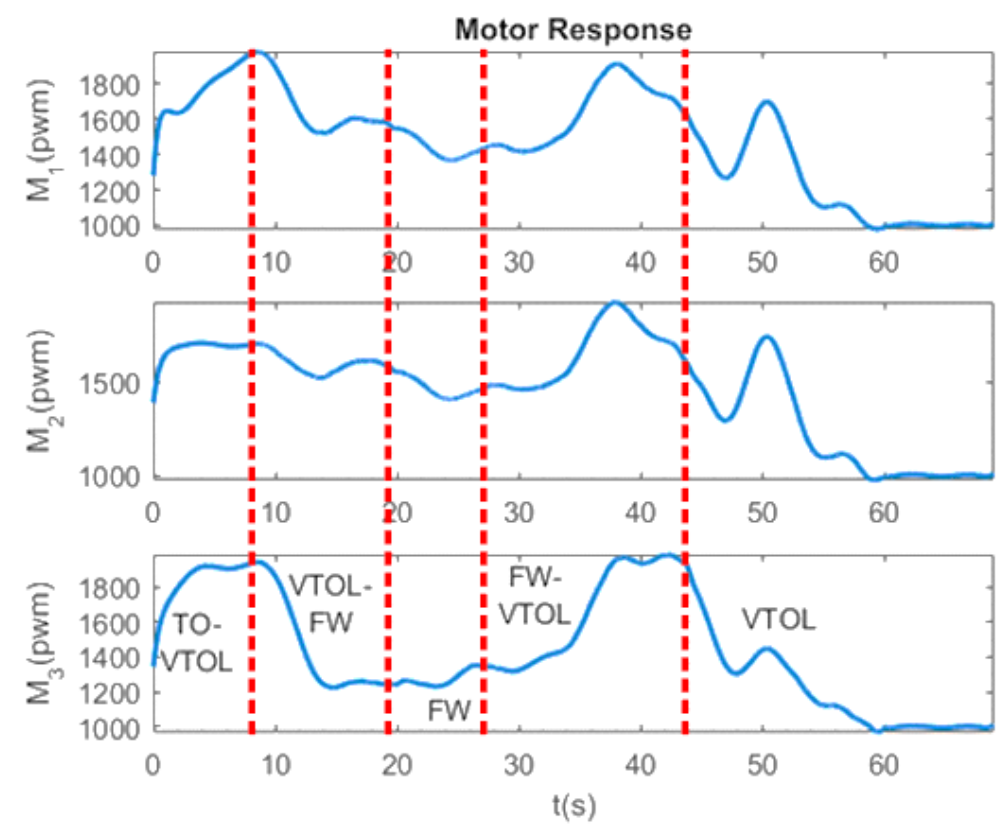

Figure 20. Aircraft Motor PWM Response 


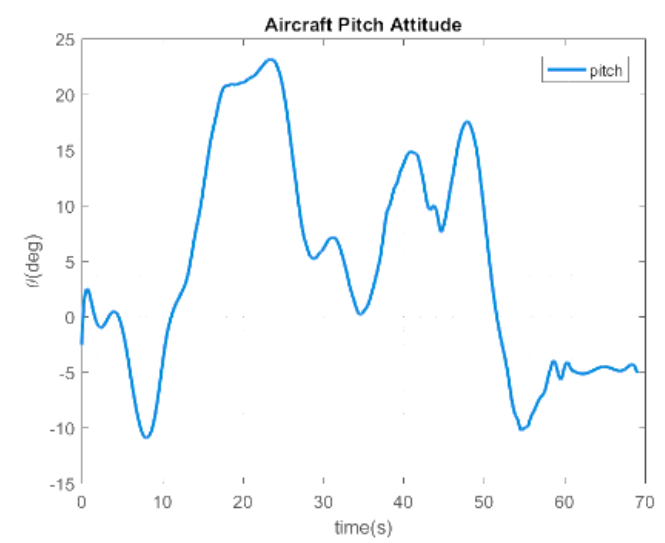

Figure 21. Aircraft Attitude (pitch) Responses

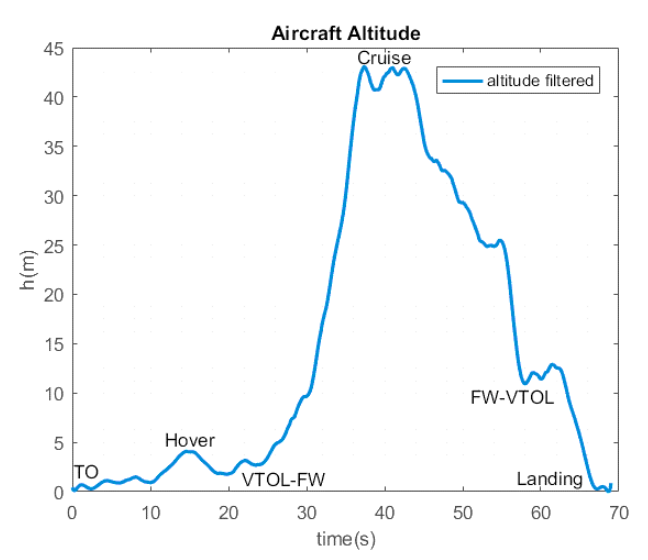

Figure 23. Aircraft Altitude Response

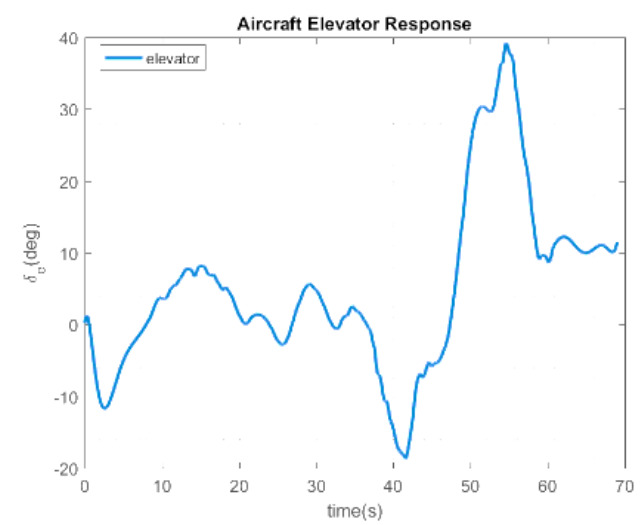

Figure 22. Aircraft Elevator Responses

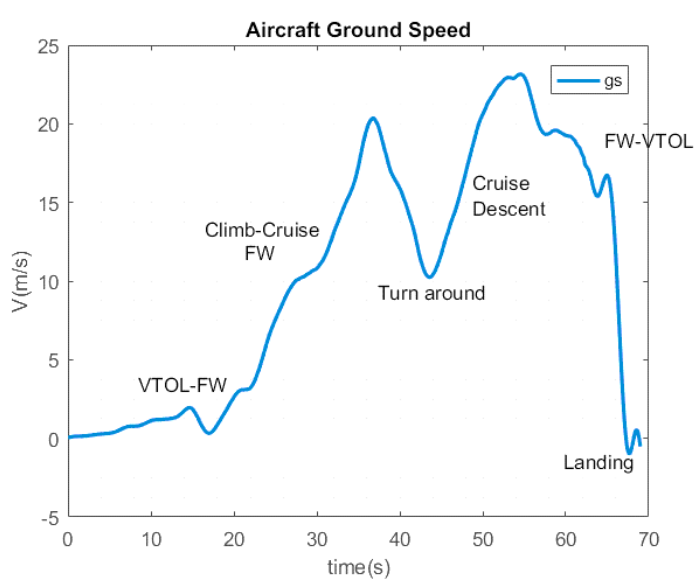

Figure 24. Aircraft Ground Speed Response

\section{Conclusions}

In this research, tiltrotor UAV has developed with initial design is 2-motor configuration. But due to lack of pitch control authority in VTOL mode that concluded from first test flight, third motor has to be added so the final configuration is 3-motor with 2 motors located at the end of main wing and 1 motor located at aft fuselage section that active in VTOL mode. At the second test flight the PID parameter was tuned so that the aircraft can hover properly despite there are disturbance in pitching and rolling axis. After second test flight successfully done, the third test flight can be conducted to test aircraft capability to performing full flight mission. The third test flight shows the aircraft can counteract pitch and rolling disturbances quite well, and when the aircraft transitioning from VTOL to FW mode its altitude was slightly reduced due to change direction of thrust. In the other hand when the aircraft is transitioning from FW to VTOL the aircraft altitude is slightly increased due to changing direction of thrust produced by main motor. In the future, 2-motorswashplate configuration will be researched to create tiltrotor that controlled by main motor only with certain feedback control method.

\section{References}

[1] Asalani, Y. K., Arif, A. A., \& Sasongko, R. A. (2020). Modelling and Analysis of Tiltrotor Aircraft Flight Dynamics Based on Numerical Simulation. AIP Conference Proceedings 2226, 030014, 1-10. 
[2] Ghiringhelli, G. L., Masarati, P., Mantegazza, P., \& Nixon, M. W. (1999). Multi-Body Analysis of a Tiltrotor Configuration. Nonlinear Dynamics 19, 333-357.

[3] Govdeli, Y., Tran, A. T., \& Kayacan, E. (2019). Multiple Modeling and Fuzzy Switching Control of FixedWing VTOL Tilt-Rotor UAV. Kearfott R., Batyrshin I., Reformat M., Ceberio M., Kreinovich V. (eds) Fuzzy Techniques: Theory and Applications. IFSA/NAFIPS 2019 2019. Advances in Intelligent Systems and Computing, vol 1000, 270-284..

[4] Ogata, K. (2010). Modern Control Engineering. Boston: Prentice Hall.

[5] Schafer, R. W. (2011). What Is a Savitzky-Golay Filter? IEEE Signal Processing Magazine, 111-117

This is an open-access article distributed under the terms of the Creative Commons Attribution 4.0 International License, which permits unrestricted use, distribution, and reproduction in any medium provided the original work is properly cited. 